Case Report

\title{
Mycobacterium tuberculosis-Associated Necrotizing Pneumonia With Adjunctive Corticosteroid Therapy
}

\author{
Ho Lam Nguyen $\mathbb{D}^{1}{ }^{1}$ Huyen Duong Thanh, ${ }^{1}$ Thuong Vu Le, ${ }^{1,2}$ and Ngoc Tran Van ${ }^{1,2}$ \\ ${ }^{1}$ Department of Internal Medicine, University of Medicine and Pharmacy at Ho Chi Minh City, Ho Chi Minh City, Vietnam \\ ${ }^{2}$ Respiratory Department, Cho Ray Hospital, Ho Chi Minh City, Vietnam
}

Correspondence should be addressed to Ho Lam Nguyen; bsholam1986@gmail.com

Received 5 January 2019; Accepted 16 June 2019; Published 1 July 2019

Academic Editor: Tomoyuki Shibata

Copyright (C) 2019 Ho Lam Nguyen et al. This is an open access article distributed under the Creative Commons Attribution License, which permits unrestricted use, distribution, and reproduction in any medium, provided the original work is properly cited.

Necrotizing pneumonia induced by Mycobacterium tuberculosis is a rare but severe condition. It is difficult to distinguish between M. tuberculosis-associated and bacterial necrotizing pneumonia. The optimal treatment for this condition is controversial. Here, we report a case of $M$. tuberculosis-associated necrotizing pneumonia treated with the adjunctive corticosteroid and the antituberculosis drugs.

\section{Introduction}

Necrotizing pneumonia is a rare but severe condition of lung parenchymal destruction commonly caused by bacterial pathogens. Necrotizing pneumonia induced by $M$. tuberculosis was reported in children recently [1], and several published cases with $M$. tuberculosis pulmonary gangrene had been reported in adults before [2]. However, optimal therapeutic strategy for this condition is still controversial [3]. Here, we report an interesting case with M. tuberculosisassociated necrotizing pneumonia treated successfully with initiation of corticosteroid followed by antituberculosis drugs.

\section{Case Report}

A 44-year-old male patient was hospitalized because of progressive dyspnea, cough, and fever during one month. His past medical history was unremarkable. He appeared initially with mild fever, dry cough, and night sweating but untreated. After two weeks, he felt shortness of breath and coughed up yellow sputum. He had been admitted in the general hospital where he had undertaken the first bronchoscopy which revealed the negative results of bronchoalveolar lavage (BAL) for both acid-fast bacillus (AFB) smear and M. tuberculosis polymerase chain reaction (PCR). He had been diagnosed with community-acquired pneumonia but not improvement after a 10-day course of antibiotic therapy and was transferred to our tertiary hospital.

On admission, he was alert, with body temperature $37^{\circ} \mathrm{C}$, pulse rate of 84 beats/min, respiratory rate of 28 breaths/ min, and blood pressure of 120/80 $\mathrm{mmHg}$. He was supplied with oxygen via bag-valve mask at $10 \mathrm{~L} / \mathrm{min}$, and the result of arterial blood gas showed $\mathrm{pH} 7.38, \mathrm{PaO}_{2} 70 \mathrm{mmHg}, \mathrm{PaCO}_{2}$ $32.7 \mathrm{mmHg}$, and $\mathrm{HCO}_{3}{ }^{-} 19.4 \mathrm{mmol} / \mathrm{L}$. Physical examination revealed dullness on percussion, fine crackles, and decreasing breath sound at the right lower lung field. Cell blood count with white blood cells $8.84 \mathrm{G} / \mathrm{L}$ (77.5\% neutrophil and $13.3 \%$ lymphocyte) and hematocrit $38.2 \%$, C-reactive protein level $78.4 \mathrm{mg} / \mathrm{L}$, and mildly elevated liver transaminase level were recorded. The rapid testing for human immunodeficiency virus was negative. Chest X-ray showed consolidation in the right lower hemithorax, and the first contrast-enhanced chest computed tomography (CT) revealed small necrotizing cavities in this consolidation area (Figure 1(a)). With aforementioned information, we suspected differential diagnoses as follows: necrotizing pneumonia with particular pathogens (high-virulence bacteria, tuberculosis, or fungal infection) or noninfectious diseases (autoimmune disease, malignancy, or vascular disease). The 


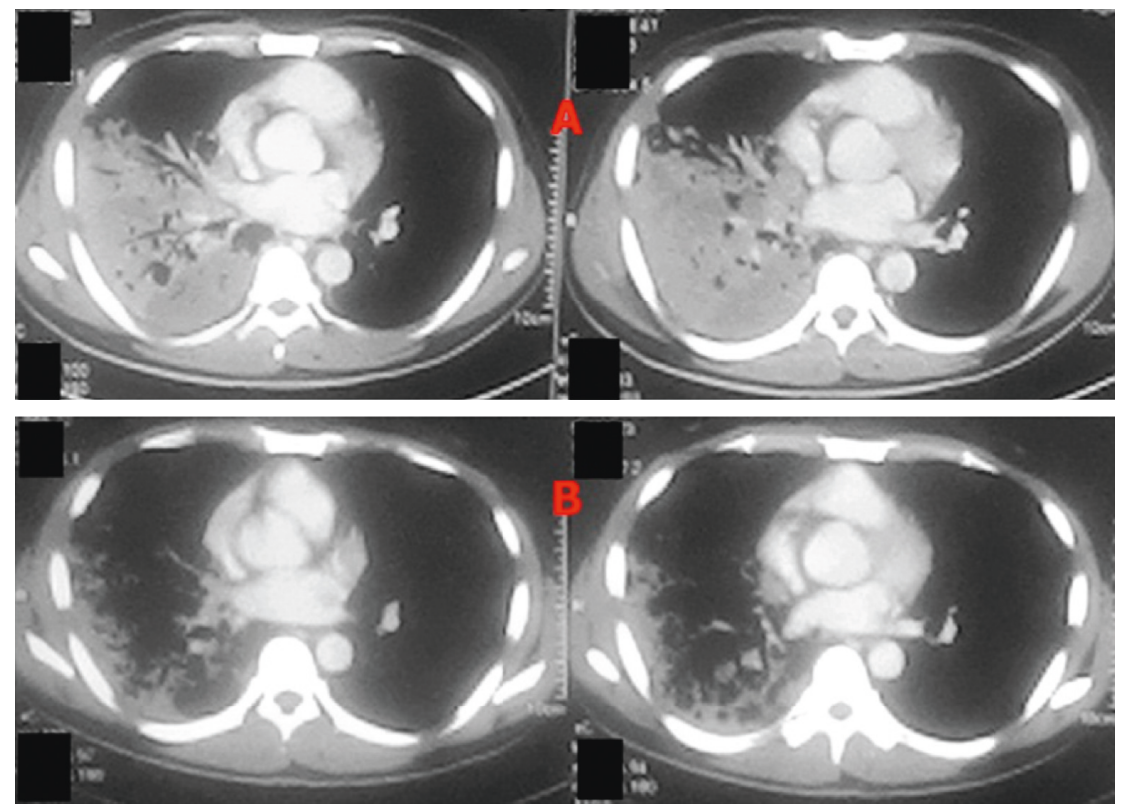

Figure 1: Two chest CT scans were undertaken 14 days apart. (a) The first chest CT showing consolidation at the right lower lobe with small cavities. (b) The second chest CT with significant amelioration of consolidation at the same lobe.

antinuclear antibodies test was negative and the histopathological result of transthoracic lung biopsy showed an inflammatory process. He was treated with the combination of broad-spectrum antibiotics (meropenem, ciprofloxacin, and vancomycin) during four days but he still had fever. The adjunctive therapy with corticosteroid (40 mg methylprednisolone intravenous once daily) was commenced, and his condition improved spectacularly (defervescence, breath normally without oxygen) but the fever reoccurred on the fourteenth day after hospitalization. The second chest CT undertaken showed a significant regression of the consolidation (Figure 1(b)). The second bronchoscopy showed the positive BAL results for AFB smear and M. tuberculosis PCR. The treatment with a six-month antituberculosis regimen resolved his condition completely on follow-up.

\section{Discussion}

In our case, diagnosis of necrotizing pneumonia associated with $M$. tuberculosis was based on the consistent chest CT (lung parenchymal consolidation with lack of perfusion, microabscesses) and the positive BAL result for $M$. tuberculosis. The destruction of pulmonary parenchyma induced by $M$. tuberculosis usually develops from months to years in most cases. Nonetheless, there are a few cases (necrotizing pneumonia and pulmonary gangrene) in which this destruction may progress rapidly causing severe respiratory failure. The pathogenic mechanism can be explained by the intensive tuberculous inflammation causing the widespread vascular thrombosis and arteritis [2]. With this atypical manifestation of pulmonary tuberculosis, it is difficult to discriminate between M. tuberculosis-associated and bacterial necrotizing pneumonia [1]. According to the best of our knowledge, this is the first reported case of $M$. tuberculosis-associated necrotizing pneumonia in adults.
The adjunctive therapy of corticosteroid showed significantly improving outcomes of patients with not only severe community-acquired pneumonia [4] but also advanced pulmonary tuberculosis $[5,6]$. Therefore, the corticosteroid treatment could be useful in management of $M$. tuberculosis-associated necrotizing pneumonia. Although the corticosteroid was initiated without antituberculosis drugs, the clinical and radiological tests showed significant improvement in our case. This can be through the beneficial effects of corticosteroid in reducing the intensive tuberculous inflammation. Moreover, the adjunctive therapy with corticosteroid should be considered in managing bacterial necrotizing pneumonia. However, using corticosteroids in these cases should be researched more before arriving at a definite conclusion.

\section{Conflicts of Interest}

No potential conflicts of interest relevant to this article were reported.

\section{References}

[1] C. Jacobs, P. Goussard, and R. P. Gie, "Mycobacterium tuberculosis, a cause of necrotising pneumonia in childhood: a case series," International Journal of Tuberculosis and Lung Disease, vol. 22, no. 6, pp. 614-616, 2018.

[2] F. A. Khan, M. Rehman, P. Marcus, and V. Azueta, "Pulmonary gangrene occurring as a complication of pulmonary tuberculosis," Chest, vol. 77, no. 1, pp. 76-80, 1980.

[3] N. Chatha, D. Fortin, and K. J. Bosma, "Management of necrotizing pneumonia and pulmonary gangrene: a case series and review of the literature," Canadian Respiratory Journal, vol. 21, no. 4, pp. 239-245, 2014.

[4] W.-F. Wu, Q. Fang, and G.-J. He, "Efficacy of corticosteroid treatment for severe community-acquired pneumonia: a meta- 
analysis," American Journal of Emergency Medicine, vol. 36, no. 2, pp. 179-184, 2018.

[5] R. A. Smego and N. Ahmed, "A systematic review of the adjunctive use of systemic corticosteroids for pulmonary tuberculosis," International Journal of Tuberculosis and Lung Disease (IJTLD), vol. 7, pp. 208-213, 2003.

[6] J. Y. Yang, M. Han, Y. Koh et al., "Effects of corticosteroids on critically Ill pulmonary tuberculosis patients with acute respiratory failure: a propensity analysis of mortality," Clinical Infectious Diseases, vol. 63, no. 11, pp. 1449-1455, 2016. 


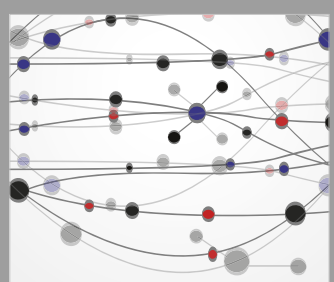

The Scientific World Journal
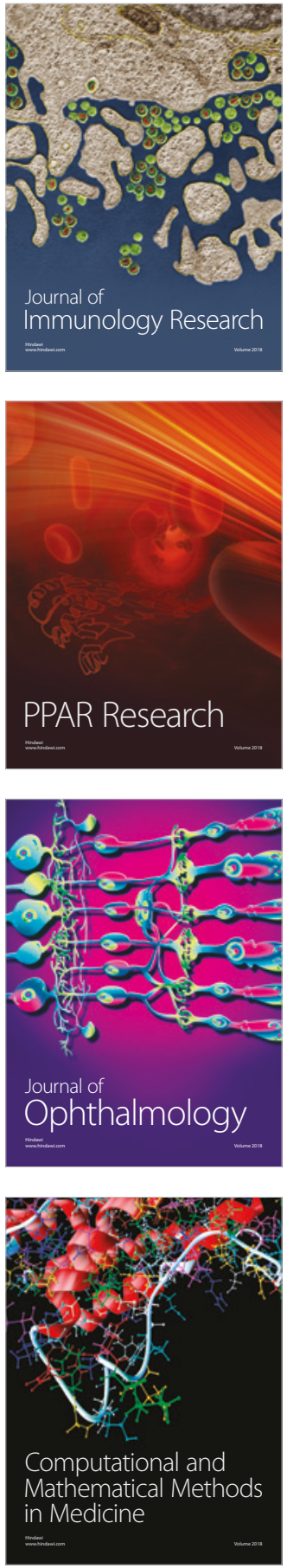

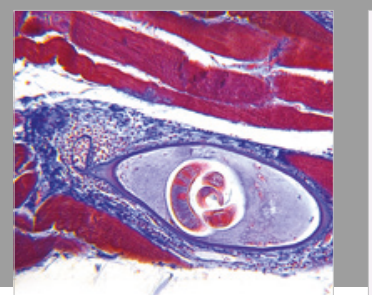

Gastroenterology Research and Practice

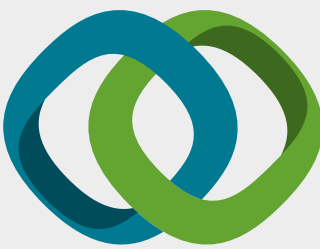

\section{Hindawi}

Submit your manuscripts at

www.hindawi.com
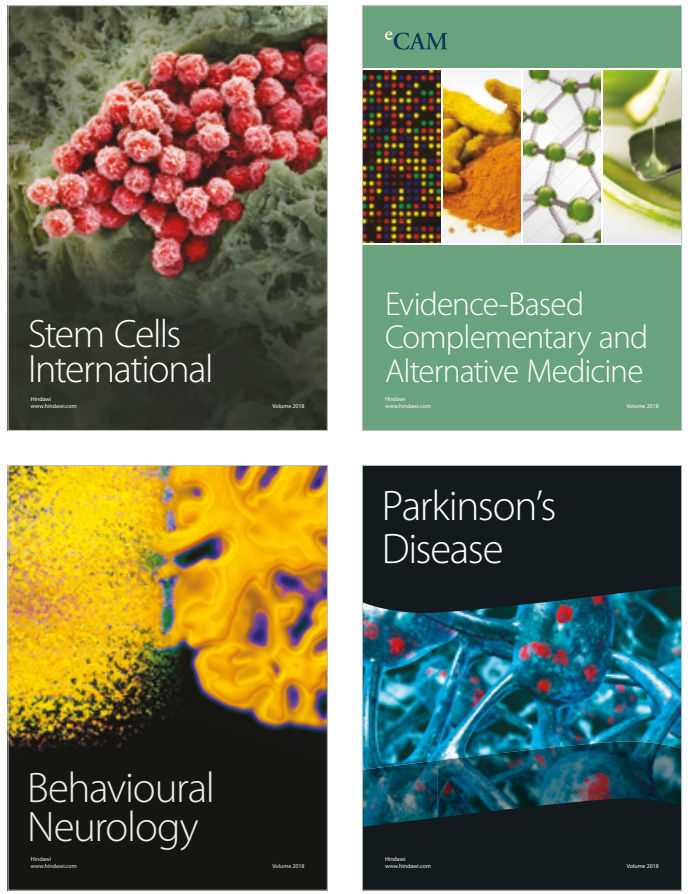

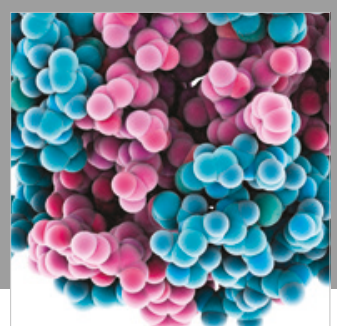

ournal of

Diabetes Research

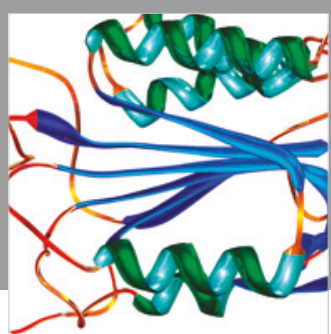

Disease Markers
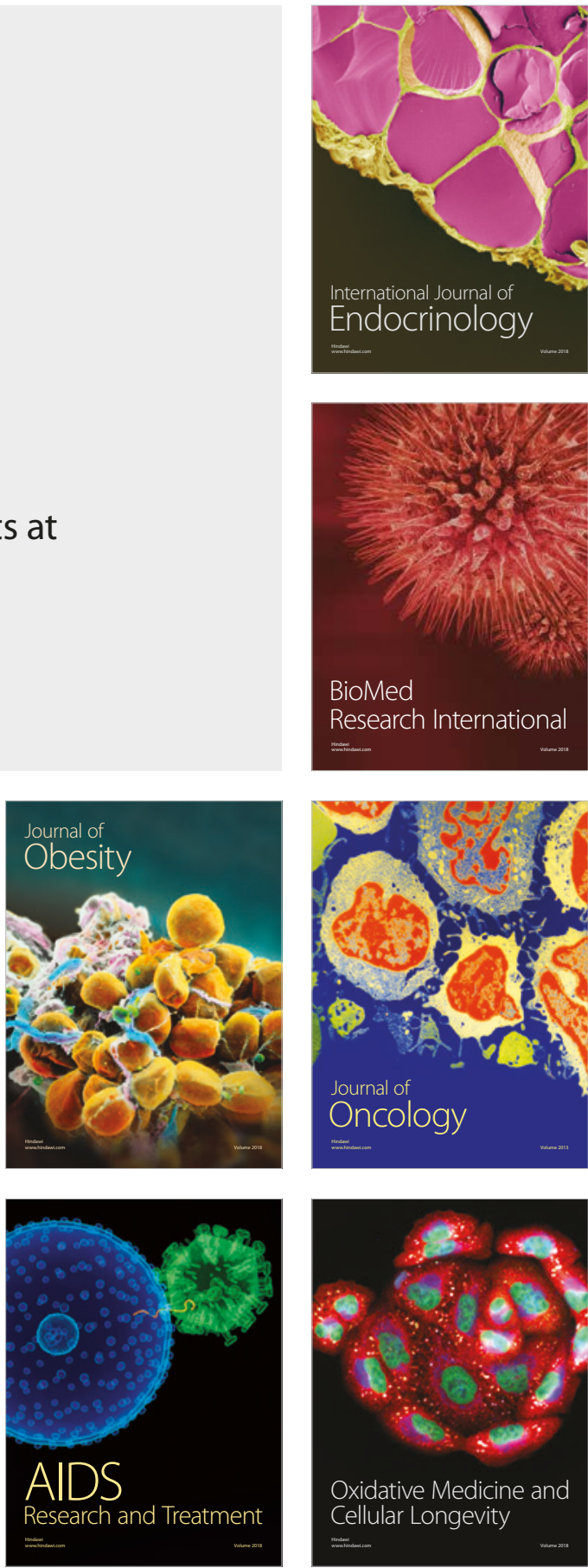